\title{
ENDOCRINOLOGICAL STUDIES IN PATIENTS WITH KLINEFELTER'S SYNDROME TREATED WITH CLOMIPHENE
}

\author{
D. A. ADAMOPOUlos, J. A. LORAINE, A. A. A. ISMAIL \\ AND G. L. FOSS \\ Medical Research Council, Clinical Endocrinology Unit, \\ 2 Forrest Road, Edinburgh EH1 2QW, and Bristol Subfertility Clinic
}

(Received 21st Fuly 1970)

\begin{abstract}
Summary. The effect of clomiphene citrate on excretion values for FSH, LH, testosterone and epitestosterone has been investigated in four patients with Klinefelter's syndrome.

During the pretreatment period, levels of FSH and LH were above the normal range for male subjects, while readings of testosterone and epitestosterone were generally low.

Clomiphene produced a significant increase in FsH output in one subject and in LH excretion in another. In the remaining patients, pituitary gonadotrophic function was not affected by the administration of the compound. The effect of clomiphene on excretion values for G-19 steroids was inconsistent.

The study did not provide definite evidence regarding the site of of action of clomiphene in patients with Klinefelter's syndrome.
\end{abstract}

\section{INTRODUCTION}

Clomiphene citrate has been widely used in the treatment of infertility in females, having been shown to be most effective in patients with secondary amenorrhoea and with the Stein-Leventhal syndrome. The compound acts as an ovarian stimulant, but the precise mechanism by which it produces its effects remains to be elucidated (see Loraine \& Bell, 1968, 1971; Papanicolaou, Loraine \& Lunn, 1970).

In normal males, clomiphene causes an increase in excretion values for the three classical oestrogens, testosterone, total 17-oxosteroids and dehydroepiandrosterone (Harkness, Bell, Loraine \& Morse, 1964; Heller, Rowley \& Heller, 1969). Effects of the compound on pituitary gonadotrophic function are variable, some investigators, e.g. Harkness, Bell, Loraine, Ismail \& Morse (1968), reporting no change in excretion values for 'total gonadotrophic activity' in urine, and others (Bardin, Ross \& Lipsett, 1967; Odell, Ross \& Rayford, 1967; Cargille, Ross \& Bardin, 1968) noting a rise in plasma levels of FsH and LH as measured by radioimmunoassay.

At the time of writing, the effect of clomiphene on endocrine function in 
infertile men has been studied to a very limited extent. Thus, in one subject with Klinefelter's syndrome, Foss, Bell, Lewis, Loraine \& Pollard (1967) failed to demonstrate any consistent effect of the compound on gonadotrophin and steroid output while in a series of oligospermic males, Mellinger \& Thompson (1966) reported that the gonadotrophin output, which was high initially, was not affected by clomiphene. The purpose of the present study is to contribute to this field by describing the results obtained when clomiphene was administered to four males suffering from Klinefelter's syndrome.

\section{MATERIALS AND METHODS}

\section{Hormone assay methods}

All patients collected complete 24-hr urine samples throughout the period of investigation, assays being conducted on 48-hr pools. Results were expressed per 24-hr urine sample. In the case of Patients 2, 3 and 4, samples were transported from Bristol to Edinburgh by train in batches two or three times per week.

The FSH and LH were extracted from urine by the tannic acid method of Johnsen (1958). The FSH was estimated using the rat ovarian augmentation test of Steelman \& Pohley (1953) incorporating the modifications described by Loraine \& Adamopoulos (1970). A total of fifty-four assays was performed; four of these $(7.4 \%)$ had to be discarded because of significant deviation from parallelism between the dose-response curves of standard (S) and unknown (U) preparations. The mean index of precision $(\lambda \pm$ S.E. $)$ was $0.07 \pm 0.02$.

The LH was estimated by the ovarian ascorbic acid depletion (OAAD) test of Parlow (1958) incorporating modifications developed in this Unit and summarized by Loraine \& Adamopoulos (1970). A total of fifty-four assays was conducted; of these, nine $(16.5 \%)$ were invalid because of lack of parallelism between $S$ and $U$. The mean index of precision $(\lambda \pm$ s.E. $)$ was $0.24 \pm 0.02$. Results of FSH and LH assays were expressed as international units (i.u.) per $24 \mathrm{hr}$ in terms of the Second International Standard for Human Menopausal Gonadotrophin (2nd IRP-HMG). Estimations of testosterone and epitestosterone in urine were performed by the method of Ismail \& Harkness (1966) as modified by Ismail, Davidson, Loraine \& Faro (1968).

\section{Clinical}

Three of the patients-2, 3 and 4-were resident in Bristol, and their clinical details are described separately in the paper by Foss \& Lewis (1971). Case 1 (M.W., Text-fig. 1) was aged 19 and unmarried; his chromosomal karyotype was $47 \mathrm{XXY}$ and $36 \%$ of the cells viewed were Barr positive. He was tall and thin (height $175 \mathrm{~cm}$; pubis to floor measurement $94 \mathrm{~cm}$; span $175 \mathrm{~cm}$ ). The penis was of normal size, but the testes were small and atrophic: there had been recent enlargement of the breasts, and the distribution of hair was of the female type. Axillary hair was absent and shaving had not commenced.

\section{Design of investigation}

All four patients collected urine samples for 1 week before clomiphene 
administration. Subjects 2, 3 and 4 were given the compound for 2 weeks, $(100 \mathrm{mg} /$ day orally) while in the case of Patient 1 , the dosage was $50 \mathrm{mg} /$ day for 1 week. Following the medication, the patients continued to collect urine for periods of time varying from 7 to 9 days.

\section{RESULTS}

Patient 1 (Text-fig. 1)

Levels of testosterone and epitestosterone during the pretreatment and

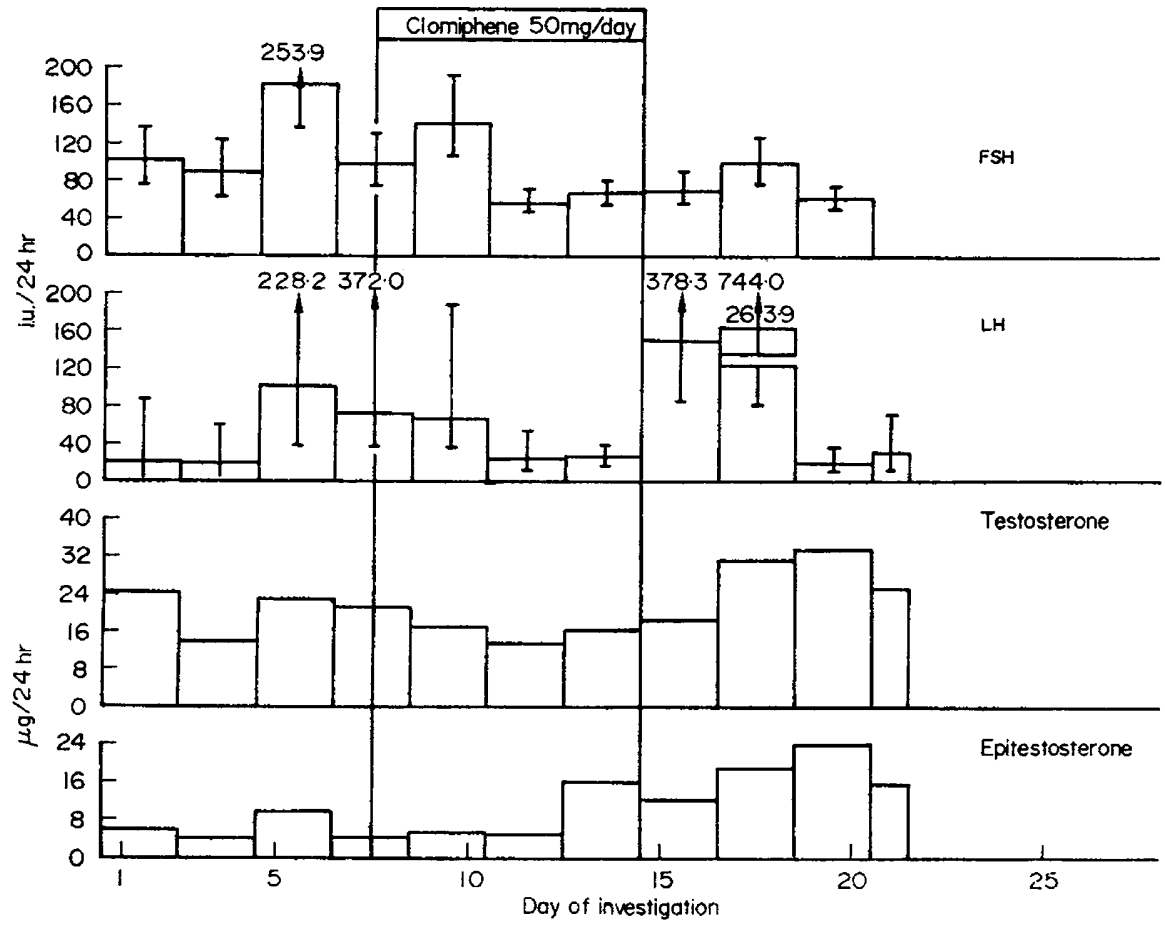

TexT-FIG. 1. Effect of clomiphene on hormone excretion in a patient with Klinefelter's syndrome (M.W., age $19 ; 47 \mathrm{XXY}$ ). Vertical bars represent fiducial limits $(P=0.95)$ of individual assays.

treatment periods were below the normal range for male subjects. Following cessation of medication, a rise in excretion values of both $\mathrm{C}-19$ steroids occurred; in the case of epitestosterone, this rise was significant $(P<0.001)$.

Throughout the study, FSH readings were grossly elevated for a male subject, being within the range normally encountered in women at and beyond the menopause; clomiphene did not affect output of this hormone. The LH readings were higher than in normal men, fluctuated considerably on a day-to-day basis and showed no consistent pattern during and following medication.

Patient 2 (Text-fig. 2)

During the control period, levels for testosterone were within the normal 
range for a male subject but readings of epitestosterone were abnormally low. Clomiphene produced no effect on excretion values for either steroid. The FSH output was consistently elevated throughout, values being within the postmenopausal range; as with Patient 1 , clomiphene did not affect excretion of this hormone. The LH readings in the control period were higher than in normal men (see Becker \& Albert, 1965; Rifkind, Kulin \& Ross, 1967). During clomiphene therapy, levels of this hormone fluctuated markedly, ranging from 32.8 to 150.0 i.u. $/ 24 \mathrm{hr}$, but due to the relatively wide fiducial limits of error of

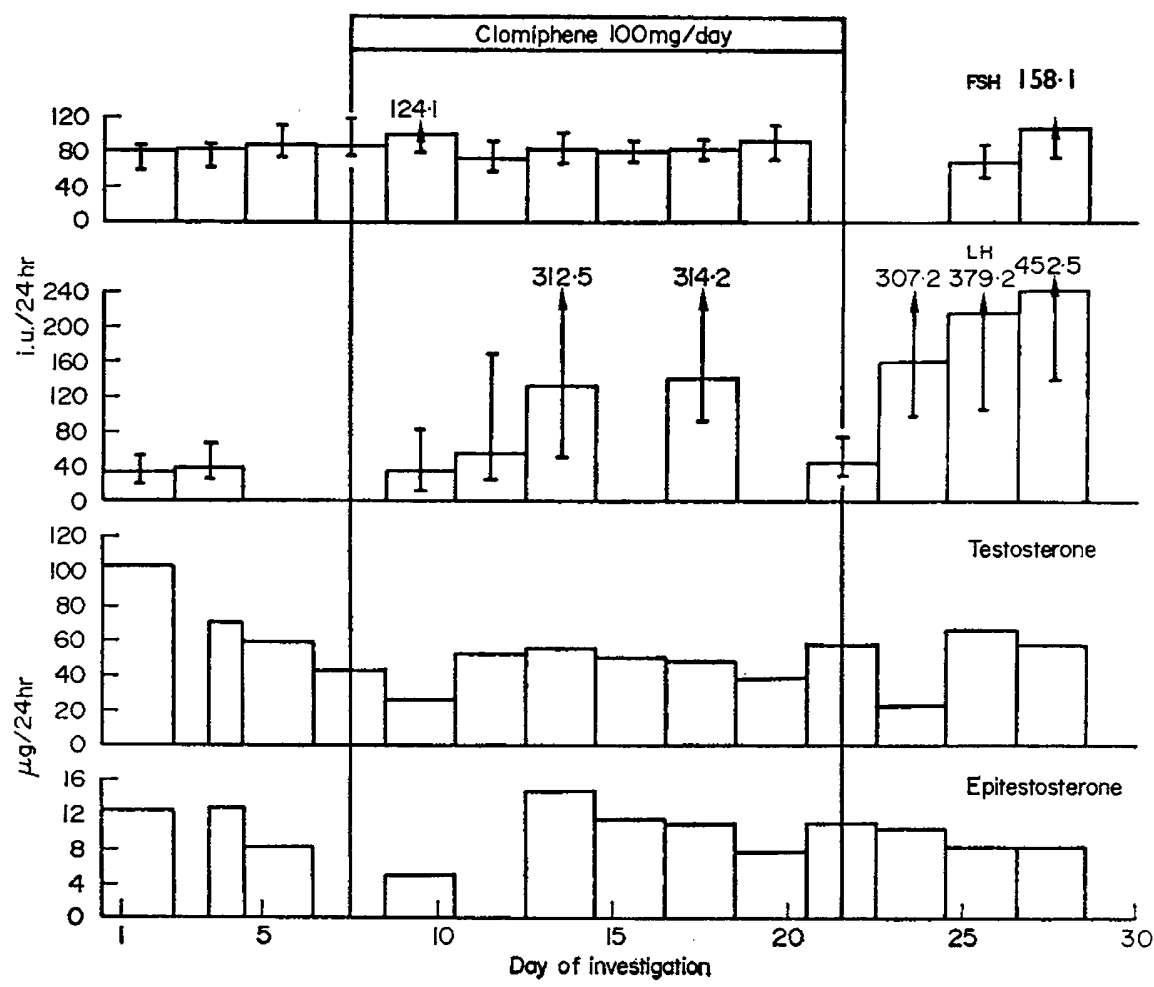

TEXT-FIG. 2. Effect of clomiphene on hormone excretion in a patient with Klinefelter's syndrome (D.G., age $30 ; 46 \mathrm{XY} / 47 \mathrm{XXY}$ mosaic). Vertical bars represent fiducial limits $(P=0.95)$ of individual assays.

individual assays, none of the readings was significantly different from those obtained during the control period. A significant rise in LH output over control values $(P<0.01)$ occurred in the post-treatment period from Day 23 of the investigation onwards.

\section{Patient 3 ( Text-fig. 3)}

In the pretreatment period, excretion values for testosterone were at the lower end of the normal range while those for epitestosterone were abnormally low. Clomiphene had no effect on the excretion of either steroid. Levels of both FSH and LH during the control period were again elevated for male subjects. 
Clomiphene produced a significant increase in FsH output $(P<0.01)$ from the 17th day of investigation onwards. The LH levels fluctuated markedly during the treatment period and showed a stepwise rise following withdrawal of medication. However, because of the overlap of the fiducial limits of individual assays, the mean $\mathrm{LH}$ excretion values during the treatment and post-treatment periods did not differ significantly from that of the control period.

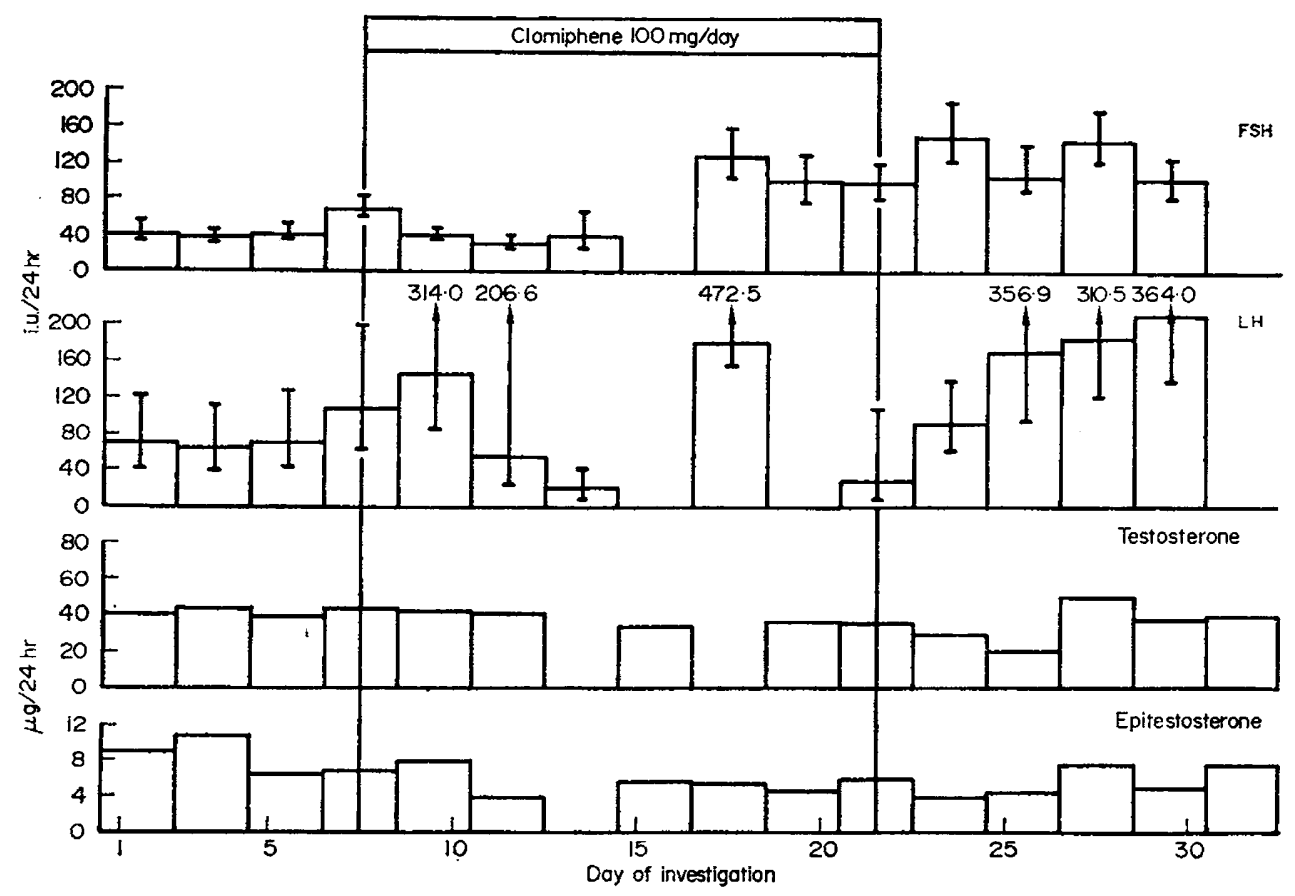

TEXT-FIG. 3. Effect of clomiphene on hormone excretion in a patient with Klinefelter's syndrome (P.T., age $30 ; 47 \mathrm{XXY})$. Vertical bars represent fiducial limits $(P=0.95)$ of individual assays.

\section{Patient 4 (Text-fig. 4)}

Values for urinary testosterone were below the normal range throughout and were unaffected by clomiphene. Epitestosterone output was low initially, declined during medication and became significantly lower than the control value $(P<0.01)$ following withdrawal of treatment. FSH and LH readings were considerably higher than in normal males and did not change appreciably as a result of medication.

\section{DISCUSSION}

In all four cases of Klinefelter's syndrome reported herein, urinary excretion values for FSH and LH during the control period were grossly elevated, such readings being compatible with the presence of primary gonadal failure. 
Values for FSH were in the same range as those reported by Papanicolaou, Bell, Ismail, Loraine \& Lunn (1967) in ambulant postmenopausal women, while LH readings were comparable to those of Papanicolaou et al. (1967) in postmenopausal subjects and of Adamopoulos, Loraine \& Dove (1971) in women approaching the menopause. In Patients 1, 2 and 4, clomiphene did not affect FSH output, while in Patient 3, a significant rise in the output of this hormone occurred towards the end of and immediately following treatment. In all patients, LH readings fluctuated considerably both during drug administration and after

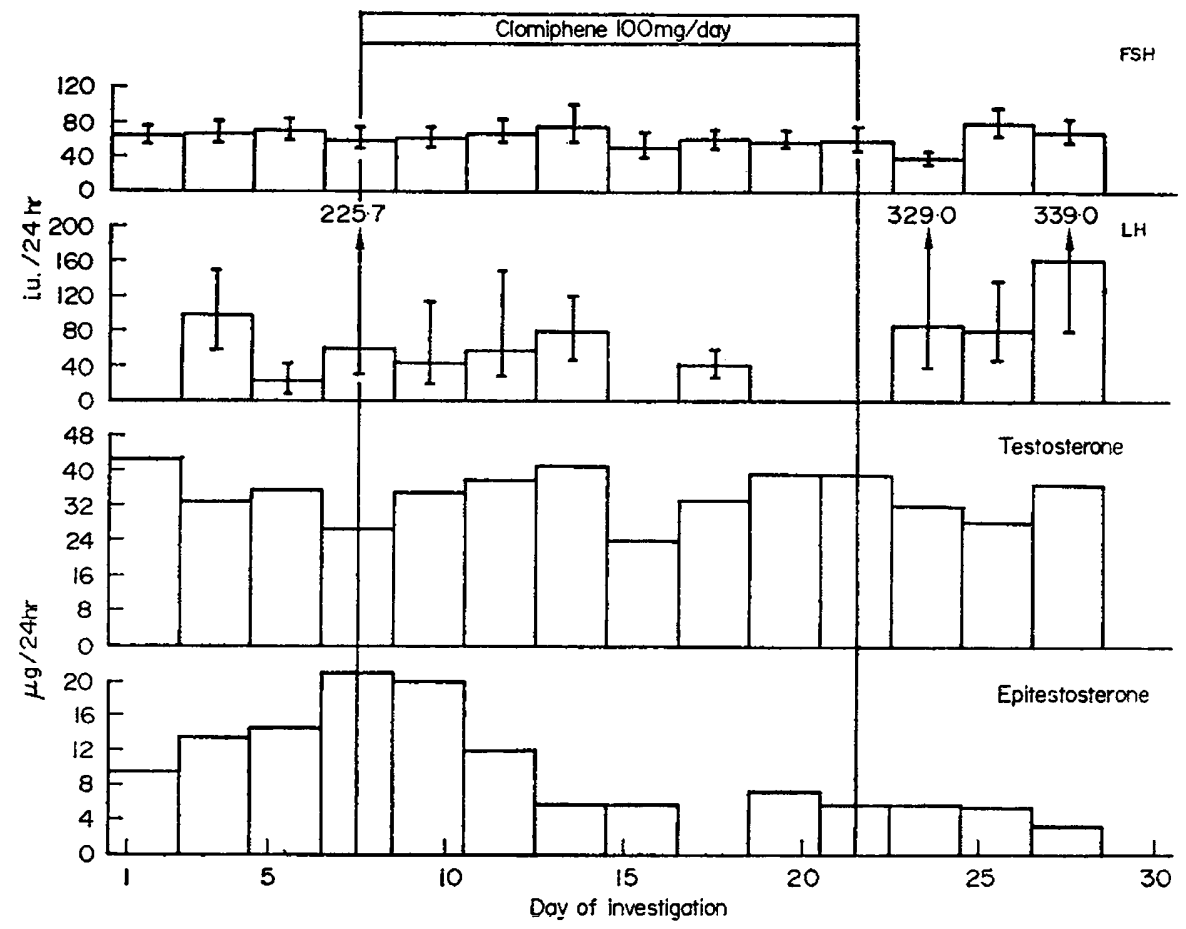

TEXT-FIG. 4. Effect of clomiphene on hormone excretion in a patient with Klinefelter's syndrome (A.W., age $31 ; 47 \mathrm{XXY})$. Vertical bars represent fiducial limits $(P=0.95)$ of individual assays.

its withdrawal, and in only one (Patient 2) did the compound produce a significant rise in excretion values for this hormone.

During the control period of Patients 1, 3 and 4, levels of testosterone and epitestosterone were below the normal range for male subjects. Only in Patient 2 were readings of testosterone normal, and it is of interest to note firstly that live spermatozoa were present in all the ejaculates (seven) examined from this patient and secondly that his chromosomal karyotype demonstrated mosaicism (Foss \& Lewis, 1971). During the treatment period, excretion values for testosterone and epitestosterone were little affected except in Patient 4 where a decline in the output of the latter steroid took place. In the post-treatment period, testosterone levels showed no consistent change in any of the four patients; in the case of epitestosterone, however, there was a significant rise in Patient 1, 
and a fall in Patient 4. The reason for the alteration in epitestosterone output in these subjects is not at present clear, and in this connection it is worth recalling that the functional rôle of this steroid in the body has not yet been satisfactorily elucidated (Ismail \& Loraine, 1968, 1969).

As indicated previously, one of the major findings to emerge from the present investigation was that clomiphene had little or no effect on pituitary gonadotrophin levels in the urine. This observation is in keeping with results reported in similar types of patient by Foss et al. (1967) and by Mellinger \& Thompson (1966). If it is postulated that the main mode of action of clomiphene is to stimulate the pituitary-hypothalamic axis, the reason for such a lack of effect is presumably due to the fact that the anterior pituitary is already functioning at maximal capacity and is unable to respond to the additional stimulus provided by clomiphene. On the other hand, if the main action of clomiphene is a direct one on the testes, the lack of effect could then be explained by the hypothesis that in Klinefelter's syndrome these glands are already under maximal stimulation by endogenously produced pituitary gonadotrophins. Further support for the view that the testes are being maximally stimulated comes from the observations of Lipsett, Davis, Wilson \& Canfield (1965), who failed to demonstrate any effect on plasma testosterone levels when HCG was administered to Klinefelter patients, and of Dupré, Brooks, Hyde, London, Prunty \& Self (1964), who reported that the concentration of testosterone in spermatic vein blood was not increased by treatment with the same hormone.

\section{AGKNOWLEDGMENTS}

We are indebted to Dr W. J. Irvine, Royal Infirmary, Edinburgh, for permission to study Patient 1 . In the performance of the assays, the skilled assistance of many technicians at the Clinical Endocrinology Unit and in particular of Miss M. A. Mackay, Miss A. V. Patek and Mr D. N. Love was much appreciated. We are grateful to Computer Services Centre, London, for performing the statistical analysis of the bioassay data. Our thanks also are due to Organon Laboratories Ltd for their generous supplies of pregnant mares serum gonadotrophin and HCG.

\section{REFERENCES}

Adamopoulos, D. A., Loraine, J. A. \& Dove, G. A. (1971) Endocrinological studies in premenopausal women approaching the menopause. $\mathcal{F}$. Obstet. Gynaec. Br. Commonw. 78, 62 .

Bardin, C. W., Ross, G. T. \& LipsetT, M. B. (1967) Site of action of clomiphene citrate in men: a study of the pituitary-Leydig cell axis. F. clin. Endocr. Metab. 27, 1558.

BECKer, K. L. \& ALBERT, A. (1965) Urinary excretion of follicle-stimulating and luteinizing hormone. 7. clin. Endocr. Metab. 25, 962.

Gargille, C. M., Ross, G. T. \& Bardin, C. W. (1968) Clomiphene and gonadotrophin in men. Lancet, ii, 1298.

Dupre, J., Brooks, R. V., Hyde, R., London, D. R., Prunty, F. T. G. \& Self, J. B. (1964) Preliminary observations on testosterone in testicular vein blood from abnormal human testes. F. Endocr. 29, Proc. vii.

Foss, G. L., Bell, E. T., Lewis, F. J. W., Loraine, J. A. \& Pollard, B. R. (1967) The effect of clomiphene on spermatogenesis and hormone excretion in a patient with Klinefelter's syndrome. 7. Reprod. Fert. 13, 315.

Foss, G. L. \& Lewis, F. J. W. (1971) A study of four cases with Klinefelter's syndrome, showing motile spermatozoa in their ejaculates. F. Reprod. Fert. 25, 401. 
Harkness, R. A., Bell, E. T., Loraine, J. A., Ismail, A. A. A. \& Morse, W. I. (1968) The effects of clomiphene on endocrine function in male subjects with adrenocortical insufficiency and following castration. Acta endocr., Copenh. 58, 38.

Harkness, R. A., Bell, E. T., Loraine, J. A. \& Morse, W. I. (1964) The effect of clomiphene on endocrine function in normal men. 7. Endocr. 31, 53.

Heller, G. G., Rowley, M. J. \& Heller, G. V. (1969) Glomiphene citrate: a correlation of its effects on sperm concentration and morphology, total gonadotrophins, ICsH, oestrogen and testosterone excretion, and testicular cytology in normal men. J. clin. Endocr. Metab. 29, 638.

Ismail, A. A. A., Davidson, D. W., Loraine, J. A. \& Faro, L. C. F. (1968) A method for the simultaneous estimation of testosterone, epitestosterone and $\Delta^{4}$-androstenedione in urine. In: Testosterone. Proceedings of the Workshop Conference at Tremsbüttel, Ed. J. Tamm. Georg Thieme, Stuttgart.

Ismail, A. A. A. \& Harkness, R. A. (1966) A method for the estimation of urinary testosterone. Biochem. 7. 99, 717.

Ismail, A. A. A. \& LoRaine, J. A. (1968) Recent studies on androgenic function in human subjects. 7. Obstet. Gynaec. Br. Commonw. 75, 929.

Ismail, A. A. A. \& LoraINe, J. A. (1969) Hirsutism: a disorder frequently associated with menstrual abnormalities. Clin. Obstet. Gynec. 12, 800.

JoHnsen, S. G. (1958) A clinical routine-method for the quantitative determination of gonadotrophin in 24 hour urine samples. Acta endocr., Copenh. 28, 69.

Lipsett, M. B., Davis, T. E., Wilson, H. \& Canfield, C. J. (1965) Testosterone production in chromatin-positive Klinefelter's syndrome. 7. clin. Endocr. Metab. 25, 1027.

Loraine, J. A. \& Adamopoulos, D. A. (1970) Recent studies on the estimation of human pituitary gonadotrophins in urine in clinical conditions. Hormones, 1, 96.

Loraine, J. A. \& BeLL, E. T. (1968) Fertility and contraception in the human female. Livingstone, Edinburgh.

Loraine, J. A. \& Bell, E. T. (1971) Hormone assays and their clinical application, 3rd edn. Livingstone, Edinburgh.

Mellinger, R. C. \& Thompson, R. J. (1966) The effect of clomiphene citrate in male infertility. Fert. Steril. 17, 94 .

Odell, W. D., Ross, G. T. \& RAyford, P. L. (1967) Radioimmunoassay for luteinizing hormone in human plasma or serum: physiological studies. 7. clin. Invest. 46, 248.

Papanicoloau, A. D., Bell, E. T., Ismail, A. A. A., Loraine, J. A. \& Lunn, S. F. (1967) Experience with urinary FSH and LH assays in patients with chromosome abnormalities. Acta endocr., Copenh. Suppl. 119, 184.

Papanicoloau, A. D., Loraine, J. A. \& Lunn, S. F. (1970) Studies on the mechanism of action of clomiphene in women with secondary amenorthoea. In: Reproductive Endocrinology, p. 60. Ed. W. J. Irvine. Livingstone, Edinburgh.

Parlow, A. F. (1958) A rapid bioassay method for LH and factors stimulating LH secretion. Fedn Proc. Fedn Am. Socs exp. Biol. 17, 402.

Rirkind, A. B., Kuliv, H. E. \& Ross, G. T. (1967) Follicle stimulating hormone (Fsh) and luteinizing hormone $(\mathrm{LH})$ in the urine of prepubertal children. 7. clin. Invest. 46, 1925.

Steelman, S. L. \& Pohley, F. M. (1953) Assay of the follicle stimulating hormone based on the augmentation with human gonadotropin. Endocrinology, 53, 604. 